\title{
Effect of functionalization of carbon nanofibers on their electronic
}

\section{conductivity}

D. Sebastián, I. Suelves, R. Moliner, M.J. Lázaro*

Instituto de Carboquímica (CSIC), C/Miguel Luesma Castán 4, 50018 Zaragoza (Spain)

* Corresponding author: Tel.: +34 976 733977; Fax: +34 976 733318; E-Mail address: mlazaro@icb.csic.es 


\begin{abstract}
The catalytic layers of a low temperature fuel cell must present a sufficient electronic conductivity for a high overall performance and, in this sense, the electrocatalyst support plays an important role. However, regarding carbon nanofibers as support, it is necessary to chemically treat their surface to improve both metal deposition and anchorage, which unfortunately affects negatively the electronic conductivity. The effects of functionalization of carbon nanofibers (CNFs) on their electronic conductivity, in addition with their physicochemical properties have been studied. Oxygen surface groups have been created on the surface of three CNFs with different properties, following three oxidation treatments with diverse severity. Whereas some important properties for their application as electrocatalyst support are not significantly modified after functionalization (texture, crystalline structure, etc.), other properties like the electronic conductivity are affected depending on the extent of the process. Refluxing at boiling temperature causes the largest reduction of electronic conductivity, of ca. $80 \%$ when using a mixture of nitric and sulfuric acids and of ca. $50-60 \%$ when using nitric acid. On the other hand, the electronic conductivity of certain CNFs is not negatively influenced after treatment at room temperature with the mixture of nitric and sulfuric acids.
\end{abstract}




\section{Introduction}

The application of novel carbonaceous materials as electrocatalyst support in fuel cells is considered as a good opportunity to enhance the overall electrochemical activity and durability of the catalytic layers [1]. These materials differ to carbon blacks (CBs), the most spread support in fuel cell technology, both at the nanoscopic and at the macroscopic level, in terms of their texture and their morphology. Some examples are ordered mesoporous carbons, carbon gels and carbon nanofilaments, amongst others [2], [3], [4], [5], [6], [7], [8], [9], [10] and [11]. This work focuses on the study of herringbone carbon nanofibers (CNFs) with a graphite-like structure and a high ratio of exposed edge carbon atoms to basal atoms, which represents an advantage in the mentioned application [12], [13] and [14].

Among the requirements of an electrocatalyst, it is well known that the activity of a catalyst increases as the reaction surface area increases [15], [16] and [17], which means that decreasing the active phase particle size results, in principle, in an enhancement of the activity. However, depending on the reaction under consideration, the activity can also decrease when decreasing particle size under a certain limit, which is known as a particle-size effect [18]. Consequently, the surface area of the support plays an important role in the activity of the catalyst as the particle size depends on it. In addition to a high surface area, a high content of mesopores is also necessary to provide a good access to reactants/products and to maximize the number of three-phase boundary reactive sites. In highly microporous supports the active phase sinks into the micropores and the effective electrochemical reactive area is consequently reduced [9], [19] and [20].

Apart from an adequate texture, in such electrochemical applications it is of a great importance in a carbonaceous support to provide a sufficient electronic conductivity, so that the electrical resistance can be as low as possible to allow the flow of electrons. Kim et al. [21] obtained an enhancement of catalyst electroactivity when decreasing the electrical 
resistance by mixing CNFs with CBs. Moreover, the effect of the support electronic conductivity on the fuel cell performance seems to be of a great importance in high surface area supports such as amorphous activated carbons [1] and [22].

Carbon supports with a poor surface chemistry, that is, with a low content of surface functional groups, need to be chemically treated to increase their hydrophilicity and, additionally, to improve the interaction between the support surface and the active phase [23]. Zhang et al. [24] studied the structure of the Pt-C interface pointing out the importance of the presence of oxygen groups on the carbon surface for the deposition of small metal particles $(<$ $2 \mathrm{~nm}$ ). Hull et al. [25] proposed two possible Pt-C structures onto carbon nanotubes, where $\mathrm{Pt}$ bonds to ester and carbonyl oxygen atoms, whereas Plomp et al. [26] concluded that Pt anchors on carboxyl and phenol oxygen groups. Therefore, the necessary functional group for an optimum metal deposition depends on the subsequent preparation method used for the electrocatalyst synthesis.

Regarding carbon nanomaterials, which are the subject of this work, most of the literature related to their surface oxidation concerns carbon nanotubes, showing that only strong oxidizing agents are effective in creating oxygen functional groups on the carbon surface [27]. These treatments, apart from modifying the surface chemistry, may change some of the original properties of the supports like their texture, morphology or even structure.

Toebes et al. [28] found that a more severe treatment leads to a considerable increase in the surface area and pore volume of CNFs, which can be ascribed to an opening of the inner tubes of the nanofibers since the growth catalyst is removed. Recently in our group [29] the severity of the oxidation process has been observed to influence the amount of oxygen groups created but, on the other hand, the initial microscopic structure can be destroyed under highly severe treatments, thus a careful selection of the oxidizing process is mandatory. Oh et al. [10] demonstrated that, although the initial performance of the CNF-supported electrocatalysts is 
improved with functionalization, carbon corrosion is favored and thus it supposes a deleterious effect on durability.

Few works have dealt with the influence of functionalization treatments on the electronic conductivity of carbonaceous materials. The type of functionality influences the electronic behavior of the carbonaceous surface. As an example, nitrogen doped carbon nanostructures result in an enhancement of conductivity when $\mathrm{N}$ substitutes carbon atoms in the graphite matrix at a certain composition [30]. Pantea et al. [31] and [32] studied the influence of the surface chemistry of carbon blacks on their electrical conductivity at relatively low pressures $(<2 \mathrm{MPa})$. Commercial CBs without any further treatment contain small amounts of oxygen $(0.7-2.3$ at $\%)$ and sulfur $(<0.5$ at $\%)$, obtaining a general decrease of electrical conductivity as the non-carbon elements content increases, in addition to an influence of the polyaromatic and aliphatic character of carbon on the surface.

Based on a previous study of the surface chemistry of functionalized CNFs [29], this work deals with the influence of the creation of oxygen functional groups (mainly carboxyl, lactone, phenol and carbonyl) on CNFs with different properties, focusing on their electronic conductivity, as it has been shown to have an important effect on the electrochemical performance of the fuel cell.

\section{Experimental}

\subsection{Carbon Nanofiber Synthesis and Treatment}

The CNF growth catalyst, composed by $\mathrm{NiCuAl}_{2} \mathrm{O}_{3}(\mathrm{Ni}: \mathrm{Cu}: \mathrm{Al}$ molar ratio of 78:6:16), was prepared by coprecipitation of metal nitrates, calcination at $450{ }^{\circ} \mathrm{C}$ for 8 hours and reduction of $300 \mathrm{mg}$ of the catalyst precursor (a mixture of the metal oxides) under a hydrogen flow of $20 \mathrm{~mL}(\mathrm{STP}) \mathrm{min}^{-1}$ at $550{ }^{\circ} \mathrm{C}$ for 3 hours, as described elsewhere [33]. 
Three growth conditions were employed to obtain CNFs with different physico-chemical properties, according to recent previous works [34] and [35], and were labeled as CNF 1, obtained at $700{ }^{\circ} \mathrm{C}$ and $4 \mathrm{~L}(\mathrm{STP}) \mathrm{gcat}^{-1} \mathrm{~h}^{-1}$; CNF 2, obtained at $600^{\circ} \mathrm{C}$ and $4 \mathrm{~L}(\mathrm{STP}) \mathrm{g}_{\mathrm{cat}}{ }^{-1} \mathrm{~h}^{-1}$; and CNF 3, obtained at $550^{\circ} \mathrm{C}$ and $10 \mathrm{~L}(\mathrm{STP}) \mathrm{g}_{\mathrm{cat}}{ }^{-1} \mathrm{~h}^{-1}$. The growth process was performed in a fixed-bed vertical quartz reactor with $16 \mathrm{~mm}$ of inner diameter. Typically, $300 \mathrm{mg}$ of the catalyst are placed into the reactor and heated by an electric furnace, under nitrogen flow, up to the desired temperature. Then, the reactant feed $\left(\mathrm{CH}_{4}\right.$, Air Products), with a total pressure of $1 \mathrm{~atm}$, flows through the catalyst sample for $620 \mathrm{~min}$. The outlet flow is hourly analyzed by gas chromatography using a Varian CP4900 chromatograph. At the end the reactor is slowly cooled under nitrogen flow to room temperature. The methane to carbon conversion is determined during the process by the difference in the reagent concentrations at the reactor inlet and outlet and a simple mass balance.

CNFs were subsequently functionalized by oxidation treatments, refluxing with concentrated acid solutions of $\mathrm{HNO}_{3}$ or $\mathrm{HNO}_{3}: \mathrm{H}_{2} \mathrm{SO}_{4}$. In these solutions the nitronium ion, $\mathrm{NO}_{2}{ }^{+}$, is able to attack the carbonaceous surface, which is presumably the first step in the introduction of oxygen surface groups. The severity of the treatment increases in the order $\mathrm{HNO}_{3}<1: 1$ $\mathrm{HNO}_{3}: \mathrm{H}_{2} \mathrm{SO}_{4}$ [28]. Three oxidation conditions were employed, namely 'A': a mixture of concentrated nitric and sulfuric acids $(1: 1)$ at room temperature; 'B': a mixture of concentrated nitric and sulfuric acids $(1: 1)$ at boiling temperature; and ' $\mathrm{C}$ ': concentrated nitric acid at boiling temperature. The duration of the treatments was 30 minutes in all cases. The acid concentrations employed were $65 \%$ for nitric acid and $96 \%$ for sulfuric acid in water, as purchased to Panreac. After oxidation, samples were thoroughly washed with deionized water until neutral $\mathrm{pH}$ and subsequently dried at approximately $100{ }^{\circ} \mathrm{C}$ overnight.

\subsection{Carbon Nanofibers Physico-Chemical Characterization}


The nature and characteristics of carbon nanofibers obtained in the experiments previously described were studied using temperature programmed desorption (TPD), nitrogen physisorption, X-ray diffraction (XRD), scanning electron microscopy (SEM) and temperature programmed oxidation (TPO).

The quantitative and qualitative determination of the oxygen surface groups was carried out by means of TPD experiments. Typically, $300 \mathrm{mg}$ were placed in a U-shaped quartz reactor. The temperature was increased at a rate of $10^{\circ} \mathrm{C} \mathrm{min}^{-1}$ from room temperature up to $1050{ }^{\circ} \mathrm{C}$ under a helium flow of $30 \mathrm{~mL}(\mathrm{STP}) \mathrm{min}^{-1}$. The amounts of $\mathrm{CO}$ and $\mathrm{CO}_{2}$ desorbed from the carbon samples were analyzed by gas chromatography.

Textural properties such as specific surface area, pore volume and microporosity were calculated from nitrogen adsorption-desorption isotherms, measured at $-196{ }^{\circ} \mathrm{C}$ using a Micromeritics ASAP 2020. Total surface area and pore volume were determined using the Brunauer-Emmet-Teller (BET) equation and the single point method, respectively. Microporosity was determined from t-plot method. Pore size distribution was obtained by Barret-Joyner-Halenda (BJH) method in the adsorption isotherm.

The structural properties of CNFs were studied by X-Ray Diffraction. XRD patterns were performed using a Bruker AXS D8 Advance diffractometer, with a $\theta-\theta$ configuration and using $\mathrm{Cu} \mathrm{K \alpha}$ radiation.

The morphology of CNFs was studied by Scanning Electron Microscopy (SEM) using a Hitachi S-3400 N.

Finally, stability under oxidation conditions was studied by Temperature Programmed Oxidation (TPO). TPO experiments were carried out under a flow of air using a heating rate of $5{ }^{\circ} \mathrm{C} \mathrm{min}{ }^{-1}$ from room temperature up to $850^{\circ} \mathrm{C}$ on a thermogravimetric analyzer Setaram. 


\subsection{Electronic Conductivity}

The electrical resistance that a powdered material offers to electrical current is a combination of the individual resistances of both the grains and the contacts between them. Consequently, measuring the conductivity of a powder requires pressing on the bed of grains in order to ensure the electrical contact [36]. The device used with this purpose consists on a thick-walled PVC tube with an inner diameter of $8 \mathrm{~mm}$. A scheme of the experimental set-up and the equivalent electrical circuit are described elsewhere [35]. The bottom of the cylinder is closed by a stationary brass piston and, after introducing $2 \mathrm{~cm}^{3}$ of grinded and weighed sample, the upper side is closed by a stainless steel plunger, allowed to move down in the cylinder. Then weighed loads are put on the upper piston and the pressure reaches values from 0.6 MPa to 9.3 MPa, which are high enough to allow good electrical contacts between grains, but too low to cause the crushing of the particles.

The height of the sample is measured using a digital micrometer Mitutoyo with an accuracy of $\pm 0.02 \mathrm{~mm}$. Then the DC electrical resistance of the pressed powder is determined by a twoprobe method. Known values of voltage are then applied by a power supply Array 3645A, scanning current values up to $20 \mathrm{~mA}$, and the voltage drop in the resistors (sample and calibrated) are measured with a 61/2 digits Array M3500A multimeter. Electrical conductivity is then calculated from resistance value, obtained in turn from the adjustment of voltage and current slope, and geometric parameters. 


\section{Results}

\subsection{Carbon Nanofiber Growth, Functionalization and Physico-Chemical Characterization}

The carbon deposition process from methane decomposition was followed by gas chromatography and the results obtained are plotted in figure 1.

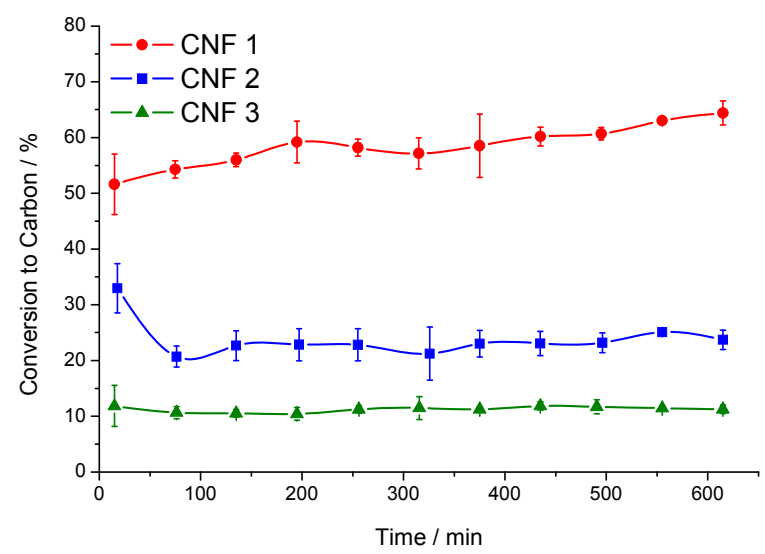

Figure 1. Methane to carbon conversion for the three growth conditions of CNFs: CNF 1, 700 ${ }^{\circ} \mathrm{C}$ and $4 \mathrm{~L} \mathrm{~g}_{\text {cat }}{ }^{-1} \mathrm{~h}^{-1}$; CNF 2: $600{ }^{\circ} \mathrm{C}$ and $4 \mathrm{~L} \mathrm{~g}_{\mathrm{cat}}{ }^{-1} \mathrm{~h}^{-1}$; CNF 3: $550{ }^{\circ} \mathrm{C}$ and $10 \mathrm{~L} \mathrm{~g}_{\text {cat }}{ }^{-1} \mathrm{~h}^{-1}$.

As can be observed, the methane to carbon conversion does not present any significant deactivation during the growth process, increasing with reaction temperature from $10 \%$ for $\mathrm{CNF} 3\left(550^{\circ} \mathrm{C}\right)$ up to $60 \%$ for $\mathrm{CNF} 1\left(700^{\circ} \mathrm{C}\right)$. The growth rate remains consequently constant, leading to a rather homogeneous distribution of carbon nanofibers, corroborated by SEM micrographs figures 2(a), 2(c) and 2(e). Afterwards, the as-obtained CNFs were oxidized and characterized.
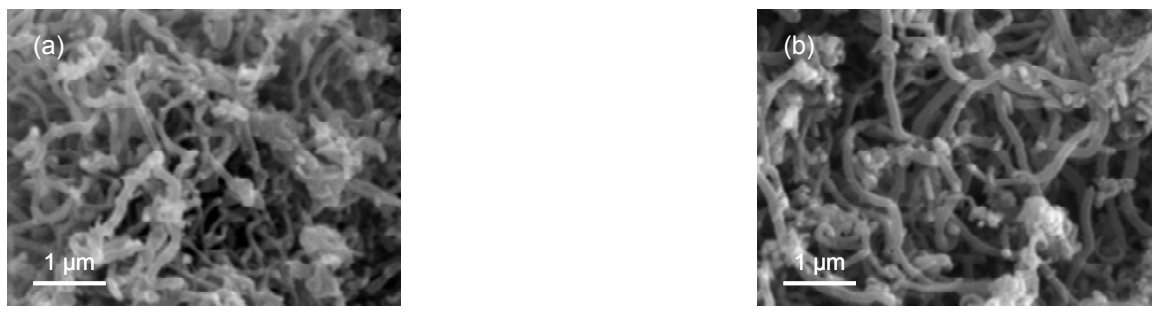

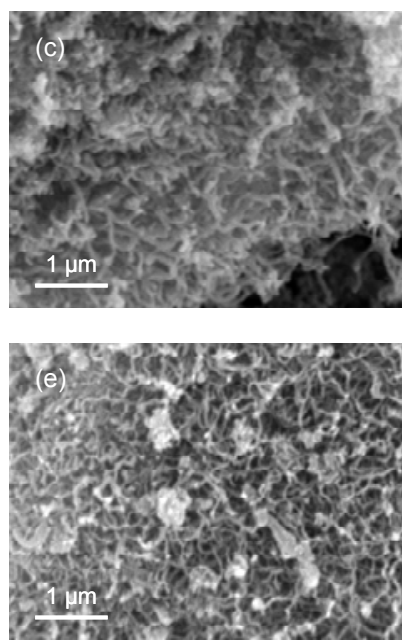

Figure 2. SEM micrographs of (a) CNF 1; (b) CNF 1-A; (c) CNF 2; (d) CNF 2-C; (e) CNF 3; (f) CNF 3-B.

The main objective of the functionalization process is to modify the surface chemistry of CNFs, specifically increasing the amount of surface oxygen groups of a certain interesting type, depending on the subsequent process of platinum deposition. The study of the surface

chemistry was carried out by means of TPD experiments. The evolutions of desorbed $\mathrm{CO}_{2}$ and $\mathrm{CO}$ with temperature for each of the samples are shown in figures 3(a) and 3(b) respectively.
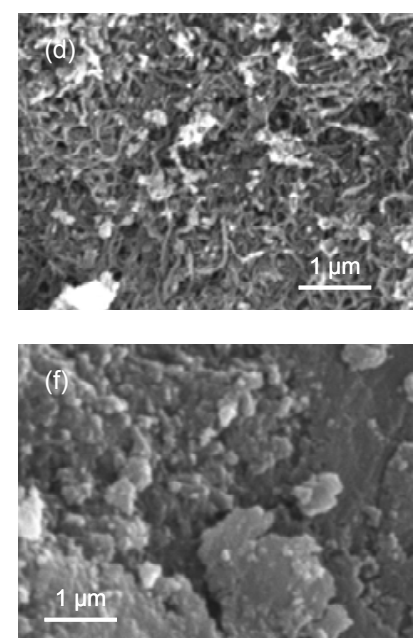
(a)
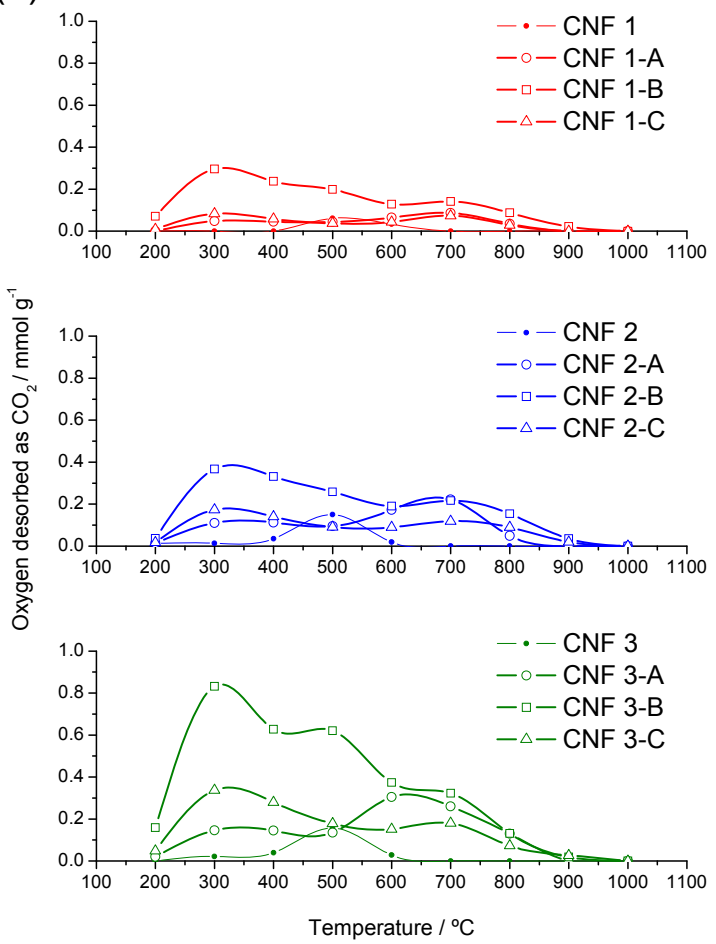

(b)
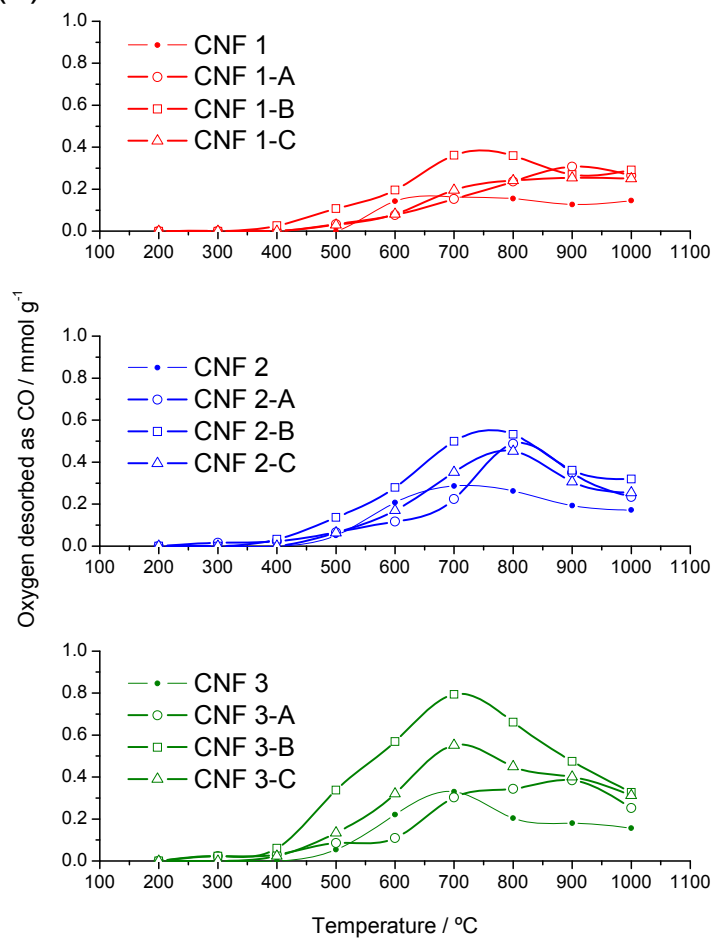

Figure 3. Evolution of oxygen desorbed as (a) $\mathrm{CO}_{2}$ and (b) $\mathrm{CO}$ from CNFs, during the TPD experiments.

The total amounts of oxygen are presented in table 1, calculated from TPD data. Untreated samples contain a small amount of oxygen (1.5-2.6 wt \%). The largest creation of oxygen groups, independently of the CNF, was obtained with oxidation in the mixture of $\mathrm{HNO}_{3}$ and $\mathrm{H}_{2} \mathrm{SO}_{4}$ at boiling temperature (B) with $6.4 \mathrm{wt} \%, 8.5 \mathrm{wt} \%$ and $15.1 \mathrm{wt} \%$ for CNF $1, \mathrm{CNF} 2$ and CNF 3 respectively. A and C oxidation treatments lead to a similar oxygen content, about two times higher than the corresponding original CNF. The number of oxygen atoms per surface area is also presented, considering the specific surface area from BET calculations on the $\mathrm{N}_{2}$ physisorption experiments. Similar trends were found among CNFs considering the same oxidizing treatment. 
Table 1. Composition of oxygen functional groups on the surface of CNFs, obtained from TPD analyses.

\begin{tabular}{|c|c|c|c|c|c|c|c|}
\hline Sample & $\begin{array}{l}\text { Total O } \\
\text { content } \\
\text { wt } \%\end{array}$ & $\begin{array}{l}\mathrm{O} \\
\text { atoms } / \mathrm{nm}^{2} \\
\text { a }\end{array}$ & $\begin{array}{l}\text { Composition } \\
\text { Carboxylic } \\
\text { molar \% }\end{array}$ & $\begin{array}{l}\text { Anhydride } \\
\text { molar \% }\end{array}$ & $\begin{array}{l}\text { Lactone } \\
\text { molar } \%\end{array}$ & $\begin{array}{l}\text { Phenol } \\
\text { molar \% }\end{array}$ & $\begin{array}{l}\text { Carbonyl/ } \\
\text { Quinone } \\
\text { molar \% }\end{array}$ \\
\hline CNF 1 & 1.5 & 6.4 & 1.8 & 7.9 & 0.0 & 30.8 & 59.4 \\
\hline CNF 1-A & 2.8 & 10.2 & 6.7 & 0.0 & 16.6 & 1.6 & 75.2 \\
\hline CNF 1-B & 6.4 & 22.8 & 22.9 & 2.9 & 17.2 & 18.7 & 38.2 \\
\hline CNF 1-C & 2.8 & 11.2 & 11.5 & 0.9 & 11.7 & 11.7 & 64.2 \\
\hline CNF 2 & 2.6 & 6.9 & 8.0 & 8.5 & 1.3 & 36.8 & 45.5 \\
\hline CNF 2-A & 4.9 & 11.7 & 10.7 & 5.0 & 19.7 & 0.0 & 64.5 \\
\hline CNF 2-B & 8.5 & 19.8 & 20.9 & 3.0 & 19.6 & 20.8 & 35.7 \\
\hline CNF 2-C & 4.9 & 10.8 & 14.7 & 1.2 & 16.0 & 17.8 & 50.3 \\
\hline CNF 3 & 2.6 & 5.3 & 8.5 & 5.1 & 5.0 & 29.7 & 51.7 \\
\hline CNF 3-A & 6.1 & 12.4 & 11.2 & 6.6 & 27.6 & 3.6 & 51.0 \\
\hline CNF 3-B & 15.1 & 34.8 & 25.3 & 4.7 & 20.9 & 22.2 & 26.9 \\
\hline CNF 3-C & 7.6 & 13.7 & 19.7 & 2.9 & 15.0 & 21.4 & 41.0 \\
\hline
\end{tabular}

${ }^{\mathrm{a}}$ Considering the BET surface area calculated from $\mathrm{N}_{2}$ physisorption isotherms.

Table 1 also summarizes the estimated distribution of oxygen functional groups obtained from the deconvolution of TPD curves. According to previous publications [37] and [38], some assumptions were made to determine the relative amount of each surface group by the deconvolution of $\mathrm{CO}_{2}$ and $\mathrm{CO}$ curves. $\mathrm{CO}_{2}$ evolution is decomposed into three contributions corresponding to carboxylic acids, anhydrides and lactones. One mol of an anhydride group decomposes releasing one mol of $\mathrm{CO}$ and one mol of $\mathrm{CO}_{2}$, thus the corresponding peak must have the same shape and magnitude in the deconvolution of both $\mathrm{CO}$ and $\mathrm{CO}_{2}$ curves. Apart from anhydrides, the $\mathrm{CO}$ curve decomposes into phenols and carbonyl/quinones. More information about the desorption of oxygen functional groups can be found elsewhere [37, 
39]. A Gaussian function was used to fit each functional group contribution and the corresponding addition of Gaussian curves was fitted minimizing the square of the deviations by a numerical routine (conjugate gradient method).

Untreated CNFs contain a small total amount of carbonyl (45-60\% of total) and phenolic (30$37 \%$ ) groups desorbing as $\mathrm{CO}$, followed by anhydrides (5-9\%) desorbing as $\mathrm{CO}$ and $\mathrm{CO}_{2}$. Oxidation $\mathrm{B}\left(\mathrm{HNO}_{3}: \mathrm{H}_{2} \mathrm{SO}_{4}\right.$ at boiling temperature) mainly creates carboxylic acids (first peak in $\mathrm{CO}_{2}$ desorption graph) and lactones (last peak in $\mathrm{CO}_{2}$ desorption graph), increasing at the same time the total number of phenolic and carbonyl groups. CNFs oxidized by A $\left(\mathrm{HNO}_{3}: \mathrm{H}_{2} \mathrm{SO}_{4}\right.$ at room temperature) and $\mathrm{C}\left(\mathrm{HNO}_{3}\right.$ at boiling temperature $)$ treatments, although similar in the total amount of oxygen created, differ in composition. The mixture of $\mathrm{HNO}_{3}$ and $\mathrm{H}_{2} \mathrm{SO}_{4}$ at room temperature (A) favors the formation of lactones, whereas using only $\mathrm{HNO}_{3}$ at boiling temperature (C) favors the formation of carboxylic acids and phenols. Negligible amounts of phenol groups are present after A oxidation in comparison with the other two treatments. As a general trend, the most abundant oxygen surface group after treatments is carbonyl/quinone (in the range $25-75 \%$ ), whereas the amount of anhydride groups is negligible.

These oxidizing treatments may affect the physico-chemical properties of CNFs. Table 2 summarizes the calculations from the nitrogen physisorption experiments. First of all, it has to be noted that, in the untreated CNFs, both surface area and pore volume increase from CNF 1 to $\mathrm{CNF} 3$, that is, as the synthesis temperature decreases, which is directly related to the nanofiber thickness and its dependence with temperature [34], [40] and [41]. This explains the increase in the oxygen content from CNF 1 to CNF 3 oxidized samples (table 1). The mean pore diameter also increases slightly as the temperature decreases, always in the mesopore range. 
Table 2. CNF textural properties from nitrogen physisorption measurements

\begin{tabular}{lccccc}
\hline Sample & $\begin{array}{l}\mathrm{S}_{\mathrm{BET}} \\
\mathrm{m}^{2} \mathrm{~g}^{-1}\end{array}$ & $\begin{array}{l}\text { S } \\
\mathrm{m}^{2} \mathrm{~g}^{-1}\end{array}$ & $\begin{array}{l}\text { Pore } \\
\text { Volume } \\
\mathrm{cm}^{3} \mathrm{~g}^{-1}\end{array}$ & $\begin{array}{l}\text { MicroPore } \\
\text { Volume } \\
\mathrm{cm}^{3} \mathrm{~g}^{-1}\end{array}$ & $\begin{array}{l}\text { Pore } \\
\text { Diameter } \\
\mathrm{nm}\end{array}$ \\
\hline CNF 1 & 86.8 & 7.1 & 0.30 & 0.00 & 6.0 \\
CNF 1-A & 101.1 & 10.0 & 0.38 & 0.01 & 6.1 \\
CNF 1-B & 105.1 & 8.7 & 0.40 & 0.00 & 7.1 \\
CNF 1-C & 92.6 & 12.4 & 0.29 & 0.01 & 5.8 \\
\hline CNF 2 & 142.8 & 12.6 & 0.58 & 0.01 & 6.4 \\
CNF 2-A & 158.2 & 17.7 & 0.70 & 0.01 & 6.8 \\
CNF 2-B & 162.1 & 14.3 & 0.46 & 0.01 & 7.8 \\
CNF 2-C & 172.3 & 23.5 & 0.77 & 0.01 & 7.2 \\
\hline CNF 3 & 184.9 & 18.5 & 0.72 & 0.01 & 8.3 \\
CNF 3-A & 185.0 & 23.9 & 0.69 & 0.01 & 7.5 \\
CNF 3-B & 163.0 & 14.2 & 0.21 & 0.01 & 4.9 \\
CNF 3-C & 208.6 & 31.3 & 0.71 & 0.02 & 8.2 \\
\hline
\end{tabular}

With respect to the effect of functionalization on textural properties, a slight increase of surface area was observed, whereas pore volume presented a different behavior depending on the CNF, this is, a moderate increase is observed for CNF 1 and CNF 2, whereas for CNF 3 no significant change was observed, except for CNF 3-B, presenting a decrease in surface area and pore volume. All these moderate changes in textural properties are directly related with the severity of the oxidation processes and the resistance of the CNFs. A higher degree of oxidation and a lower resistance of the carbon matter results in a fragmentation of the long fibers into shorter fragments (CNF 3-B). This morphological change was confirmed by SEM micrographs (figure 2(f)) whereas the rest of samples led to no significant change: two examples are shown in figures $2(\mathrm{~b})$ and 2 (d). On the other hand, the increase of both surface area and pore volume with oxidative treatments can be explained by a combination of the removal of growth catalyst and roughening of the surface [28]. 
X-Ray diffraction patterns can be observed in figure 4. Firstly, two peaks at $44.5^{\circ}$ and $51.6^{\circ}$ appear in the non treated samples, which correspond to the presence of nickel from the growth catalyst. After functionalization these two peaks were not observed for any of the samples, indicating that the CNF growth catalyst was, at least partially, removed during oxidation. This was further confirmed by TPO experiments.
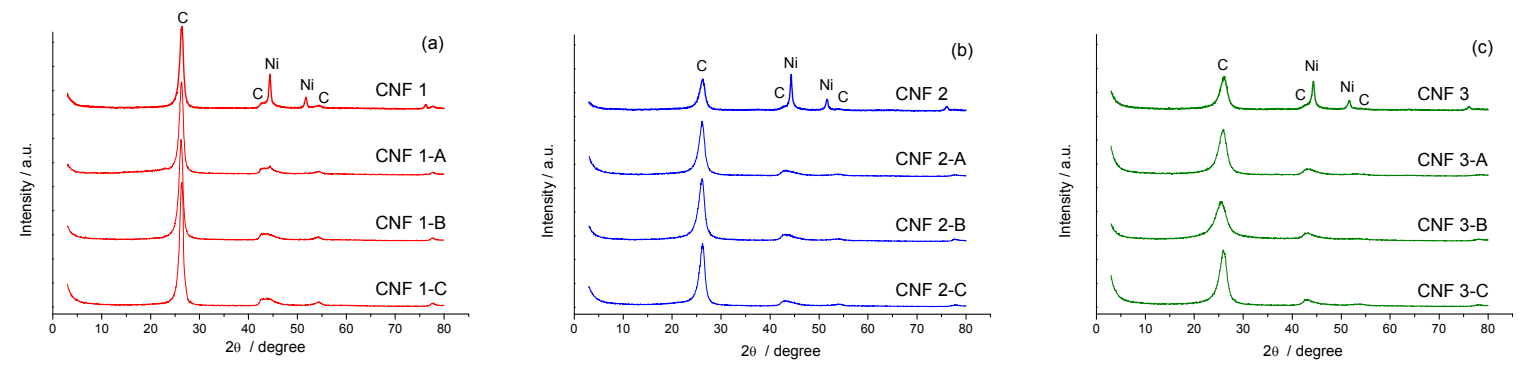

Figure 4. X-Ray Diffraction patterns of CNFs before and after oxidation treatments.

The width of the carbon peaks, specially the one with the highest intensity at $26^{\circ}$, corresponding to $\mathrm{C}\left(\begin{array}{lll}0 & 0 & 2\end{array}\right)$, increases with decreasing temperature. The full widths at half maximum from this $\mathrm{C}\left(\begin{array}{lll}0 & 0 & 2\end{array}\right)$ peak were $0.90^{\circ}, 1.33^{\circ}$ and $1.71^{\circ}$ for CNF $1, \mathrm{CNF} 2$ and CNF 3 respectively. These results indicate that a higher synthesis temperature leads to a higher graphitization degree, with a higher crystal size and lower interlayer graphene distance. After functionalization, similar crystalline structures were obtained, indicating that the introduction of oxygen surface groups on the surface does not modify the crystalline structure of the bulk CNFs. Only in CNF 3-B a considerable change is obtained, where C $\left(\begin{array}{lll}0 & 0 & 2\end{array}\right)$ peak broadens considerably from $1.71^{\circ}$ to $2.71^{\circ}$, indicating a partial destruction of the carbon crystalline structure.

The thermogravimetric analyses in the oxidation of CNFs at programmed temperature (TPO) are shown in figure 5. A sudden weight decrease occurs at temperatures between $500{ }^{\circ} \mathrm{C}$ and $700{ }^{\circ} \mathrm{C}$, depending on the sample, which is associated with carbon oxidation. Moreover, at 
higher temperatures the samples are not further oxidized and no weight change is observed, corresponding to the content of ashes of the CNF from the growth catalyst $\left(\mathrm{NiCuAl}_{2} \mathrm{O}_{3}\right)$.
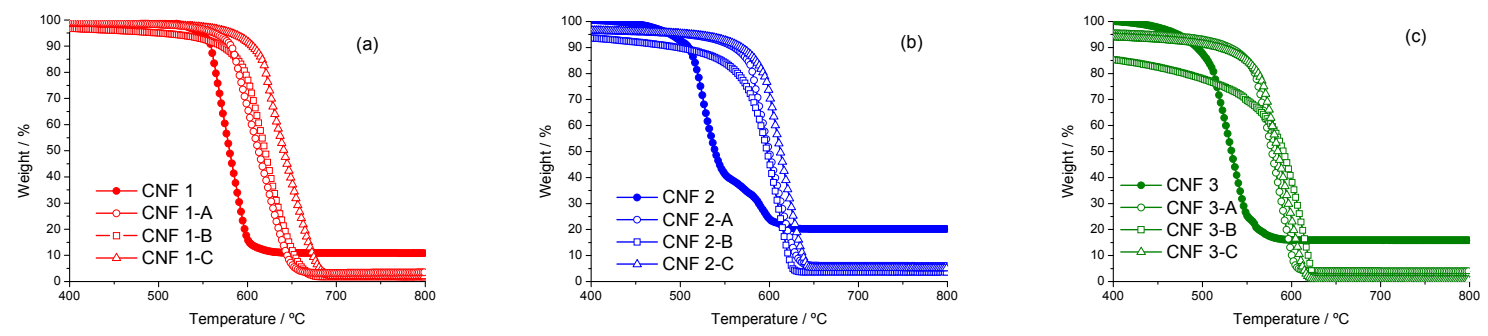

Figure 5. Thermogravimetric analyses in the oxidation in air of untreated and treated CNFs (TPO): (a) CNF 1 related samples; (b) CNF 2 related samples; (c) CNF 3 related samples.

The temperature at which the carbon samples are oxidized indicates the resistance towards oxidation in air, which depends on the graphitic character of the carbon matter as well as the surface oxidation degree. Firstly it can be observed that oxidation resistance increases in the order CNF $3<\mathrm{CNF} 2<\mathrm{CNF} 1$ in the untreated samples, according with the structural characteristics of the CNFs observed by XRD. The ash content results in $11 \%, 20 \%$ and $16 \%$ for CNF 1, CNF 2 and CNF 3 respectively, which is in agreement with the mass balance calculations during the monitoring of the growth process $(8 \%, 18 \%$ and $15 \%$ respectively).

After oxidation treatments, a considerable increase in oxidation temperature is obtained, which has already been reported in other previous works [11] and [29]. The influence of the presence of nickel on the oxidation temperature cannot be rejected, since it could act as oxidation catalyst lowering the onset temperature. In general terms, the oxidation treatment with $\mathrm{HNO}_{3}: \mathrm{H}_{2} \mathrm{SO}_{4}$ at room temperature (A) lead to the higher increase of oxidation temperature. Taking into consideration that $\mathrm{A}$ and $\mathrm{C}$ treatments lead to similar oxygen contents in CNF 1 and CNF 2, and the observed maintenance of the crystalline structure, it can be assumed that the difference in oxidation resistance of about $15-30{ }^{\circ} \mathrm{C}$ between $\mathrm{A}$ and $\mathrm{C}$ must be ascribed to a difference of functional groups composition, specifically those 
desorbing to $\mathrm{CO}$ at high temperature: carbonyl/quinone groups presumably favor higher oxidation temperatures in air.

\subsection{Electronic Conductivity}

The electronic conductivity of the CNFs in the form of powder depends on the compression pressure, increasing upon compression with a logarithmic dependence, which is related to elastic or plastic deformation of particles [42]. Particles are formed by the random aggregation of carbon nanofibers of $10 \mathrm{~nm}$ to $90 \mathrm{~nm}$ thickness, formed in turn by stacked cup graphene layers. In this kind of materials, it can be assumed that the electronic conductivity in the inside is quite high, since it is formed by graphene layers. The most important contribution to resistance is then located at the interface between nanofibers and at the interface between the particles of different aggregates [31]. Under compression, the number of electrical contacts increases due to the forced approach of neighbor particles. Figure 6 shows the relationship between the electronic conductivity and the pressure applied over the CNFs, ranging from $\sim 2 \mathrm{~S} \mathrm{~m}^{-1}$ for the lowest conductor sample at the lowest pressure, up to $\sim 388 \mathrm{~S} \mathrm{~m}^{-1}$ for the highest conductor sample at the highest pressure. CNF 1 without any posttreatment presents the highest electronic conductivity values, being the sample with the highest graphitization degree and lowest oxygen content.
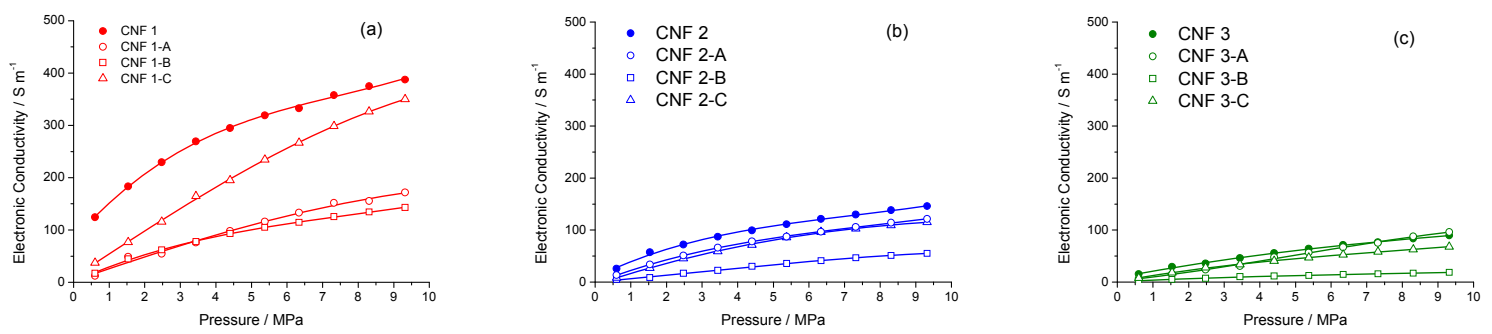

Figure 6. Variation of electronic conductivity with applied pressure: (a) CNF 1 related samples; (b) CNF 2 related samples; (c) CNF 3 related samples. 
After functionalization (A, B or C), the apparent electronic conductivity decreases for the three CNFs of this work, especially in those high conductor CNFs (CNF 1, figure 6(a)). However, different results are obtained depending on the oxidation process. For comparison purposes, the electronic conductivity must be compared among samples with similar packing fractions, that is, in which the average number of contacts between particles of the same size is comparable. As density changes after oxidation, the packing fractions are consequently different among untreated and treated CNFs under the same pressure. To illustrate this, figure 7 represents the variation of the measured density with applied pressure.

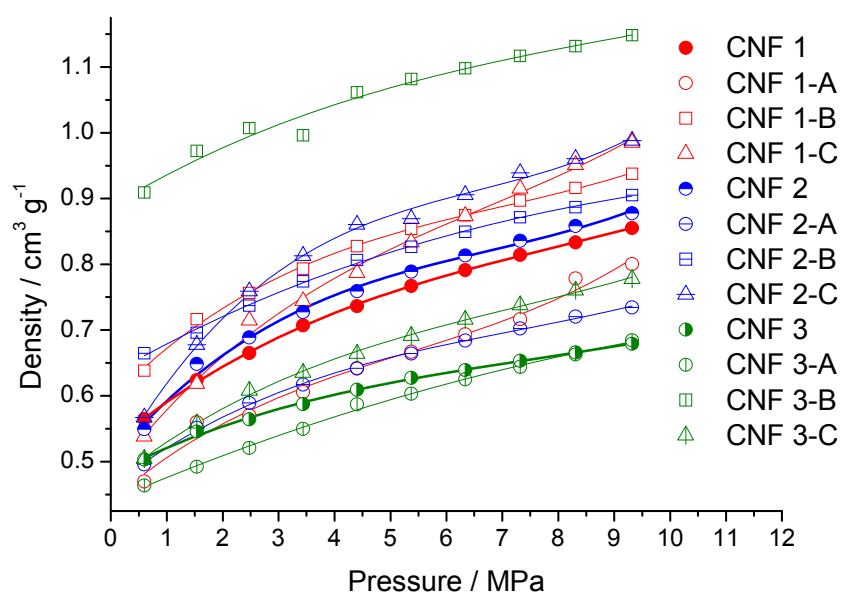

Figure 7. CNF density variation with pressure.

It must be considered that the measured density is lower than the bulk density, which could be measured by helium pycnometry and would be similar to density at much higher values of pressure. The effect of oxidation on density can be mainly attributed to morphology changes (since the macroscopic form of carbon nanofiber aggregates influences their ordering [36]); changes in composition, the removal of nickel-based catalyst (since metals are about four times denser than carbon) and the creation of oxygen surface groups; and also the possible changes in textural properties. 
Figure 8 shows the electronic conductivity of the samples versus the measured density. At similar density values it can be assumed that similar packing fractions are achieved, as the bulk material structure does not change considerably.

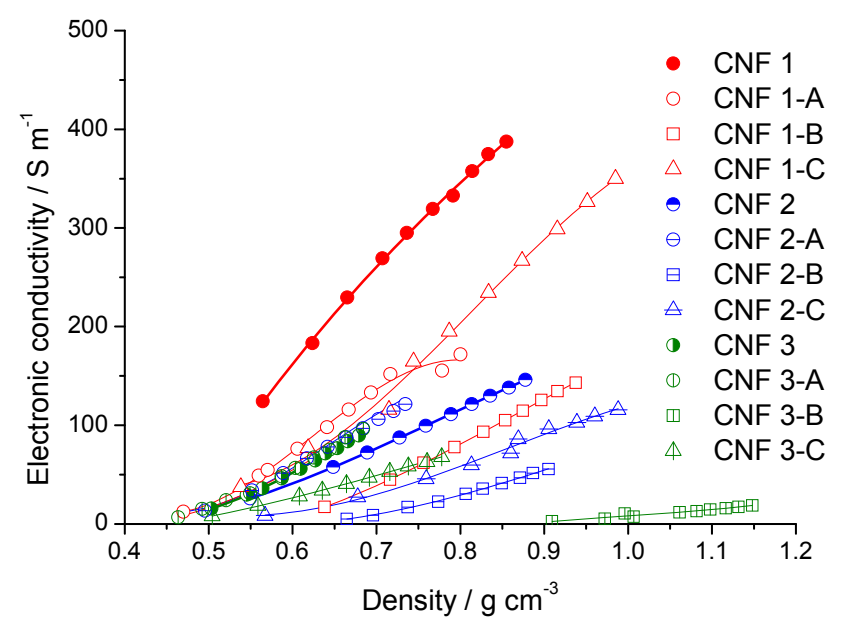

Figure 8. CNF electronic conductivity versus density.

In table 3 the estimated electronic conductivity of the samples at density values of $0.65 \mathrm{~cm}^{3} \mathrm{~g}^{-}$ ${ }^{1}, 0.70 \mathrm{~cm}^{3} \mathrm{~g}^{-1}$ and $0.80 \mathrm{~cm}^{3} \mathrm{~g}^{-1}$ are summarized for comparison. The interval of applied pressures was not enough to obtain comparable values of density for some of the samples.

Table 3. Electronic conductivity before and after functionalization

\begin{tabular}{lccc}
\hline Sample & \multicolumn{2}{l}{$\begin{array}{l}\text { Estimated electronic conductivity and percentage } \\
\text { variation with respect to untreated CNF } \\
\end{array}$} \\
& $\begin{array}{l}\mathrm{S} \mathrm{m}^{-1} \\
\text { at } 0.65 \mathrm{~cm}^{3} \mathrm{~g}^{-1}\end{array}$ & at $0.70 \mathrm{~cm}^{3} \mathrm{~g}^{-1}$ & at $0.80 \mathrm{~cm}^{3} \mathrm{~g}^{-1}$ \\
\hline CNF 1 & 213 & 260 & 345 \\
CNF 1-A & $106(-50 \%)$ & $136(-48 \%)$ & $167(-52 \%)$ \\
CNF 1-B & $20(-91 \%)$ & $39(-85 \%)$ & $80(-77 \%)$ \\
CNF 1-C & $88(-59 \%)$ & $122(-53 \%)$ & $203(-41 \%)$ \\
\hline CNF 2 & 59 & 76 & 116 \\
CNF 2-A & $83(+41 \%)$ & $111(+46 \%)$ & $*$ \\
CNF 2-B & $*$ & $9(-88 \%)$ & $29(-75 \%)$
\end{tabular}




\begin{tabular}{lccc} 
CNF 2-C & $19(-68 \%)$ & $30(-61 \%)$ & $59(-49 \%)$ \\
\hline CNF 3 & 75 & $*$ & $*$ \\
CNF 3-A & $78(+4 \%)$ & $*$ & $*$ \\
CNF 3-B & $*$ & $*$ & $*$ \\
CNF 3-C & $38(-49 \%)$ & 49 & $*$ \\
\hline
\end{tabular}

Density out of interval within the applied pressure values (0.6-9.3 MPa).

In general terms, $\mathrm{B}$ oxidation treatment (mixture of $\mathrm{HNO}_{3}: \mathrm{H}_{2} \mathrm{SO}_{4}$ at boiling temperature) leads to the highest decrease in electronic conductivity and a noticeable increase in density. At a density of $0.70 \mathrm{~cm}^{3} \mathrm{~g}^{-1}$ the electronic conductivity in CNF 1 decreases from ca. $260 \mathrm{~S} \mathrm{~m}^{-1}$ to ca. $39 \mathrm{~S} \mathrm{~m}^{-1}(-85 \%)$, and in CNF 2 from $76 \mathrm{~S} \mathrm{~m}^{-1}$ up to $9 \mathrm{~S} \mathrm{~m}^{-1}(-88 \%)$. In CNF 3-B, density values range from $0.90 \mathrm{~cm}^{3} \mathrm{~g}^{-1}$ to $1.15 \mathrm{~cm}^{3} \mathrm{~g}^{-1}$, corresponding with the already commented destruction of the original nanofiber structure, leading to the lowest values of electronic conductivity between $2 \mathrm{~S} \mathrm{~m}^{-1}$ (at $0.90 \mathrm{~cm}^{3} \mathrm{~g}^{-1}$ ) and $18 \mathrm{~S} \mathrm{~m}^{-1}$ (at $1.15 \mathrm{~cm}^{3} \mathrm{~g}^{-1}$ ). This oxidation treatment with the mixture of nitric and sulfuric acids at boiling temperature is responsible of the highest creation of surface oxygen groups, which explains the worse electrical contact between particles. It is also responsible of a considerable increase of density for the three CNFs, possibly due to a partial destruction of particle aggregates in CNF 1 and CNF 2 and the loss of the original nanofiber structure of CNF 3, pointed out in previous sections.

Oxidation treatments named $\mathrm{A}$ and $\mathrm{C}$ present a different behavior with respect to electronic conductivity. Previously it was concluded that both treatments create a very similar total content of oxygen groups, differing on their composition, and maintain the original CNF structure with slight changes in their texture. Nevertheless, density increases after C treatment (nitric acid at boiling temperature) for the three CNFs, as occurred after B oxidation, whereas a density decrease is observed after A treatment (mixture of nitric and sulfuric acids at room temperature), shown in figure 7 . 
With respect to electronic conductivity, apparently $\mathrm{C}$ oxidation process is the most conservative oxidizing treatment on CNF 1 at the same pressure, by comparison of curves in figure 6(a), achieving higher net values than the other two oxidizing treatments. On CNF 2 and $\mathrm{CNF} 3$, both $\mathrm{A}$ and $\mathrm{C}$ oxidation treatments lead to similar conductivity values, figures 6(b) and 6(c). However, considering again the effect of compaction, at a density $0.65 \mathrm{~cm}^{3} \mathrm{~g}^{-1}$, the reductions of conductivity after C treatment were $-59 \%$ for CNF 1, -68\% for CNF 2 and $49 \%$ for CNF 3. After A treatment the electronic conductivity was reduced $-50 \%$ for CNF 1 , but increased $+41 \%$ for CNF 2 and no significant change was observed for CNF 3, overlapping CNF 3 and CNF 3-A on the graph. A plausible explanation for the increase in conductivity in the sample CNF 2-A could be a change of the morphology of the aggregates, since the crystallinity does not change and the oxygen content is close to that of CNF 2-C.

To sum up, high temperatures in the oxidation process seem to affect the subsequent electronic conductivity of CNFs in a larger extent than room temperature. From the point of view of the electronic conductivity, oxidizing at room temperature with rather strong acid solutions is a better strategy than increasing the process temperature.

A general trend of the decrease of the CNF electronic conductivity with the oxygen content can be observed in figure 9. For a determined percentage of oxygen it is noticeable that a spread of conductivity data is obtained, which is due to both differences among density values (0.65-0.80 $\left.\mathrm{cm}^{3} \mathrm{~g}^{-1}\right)$ and different CNFs. Nevertheless, although the three CNFs synthesized and oxidized in this work differ in their properties, increasing the oxygen content up to $5 \mathrm{wt} \%$ entails an important reduction of electronic conductivity. A further oxidation of the carbon surface implies a softer variation in conductivity, but it must be taken into consideration that to achieve larger oxygen contents, a more severe treatment is needed, that is, utilizing higher temperature or increasing the oxidizing character of the reagents, which can even destroy the original structure of the carbon nanofibers. 


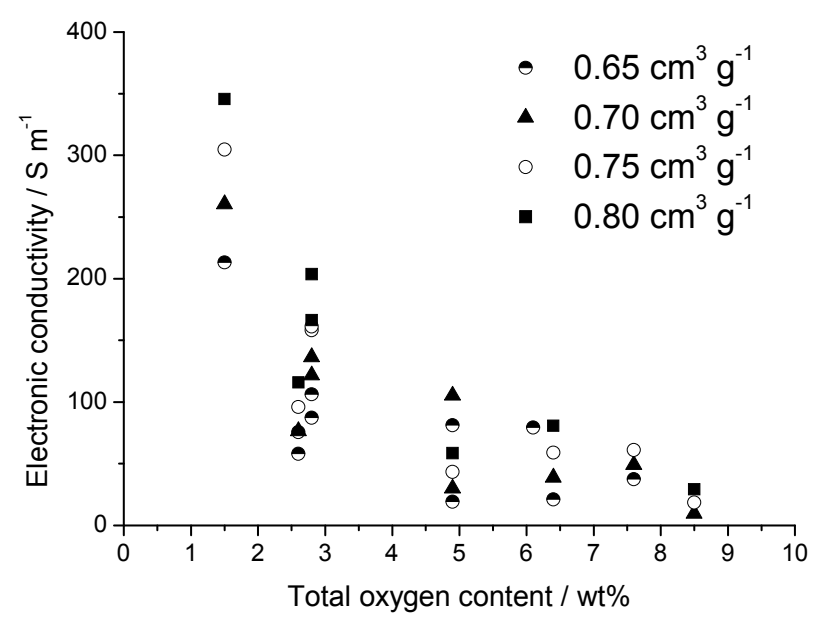

Figure 9. Influence of the oxygen total content on the electronic conductivity of CNFs.

\section{Conclusions}

Three carbon nanofibers, differing among them in their physico-chemical properties, have been functionalized by oxidizing conditions of different severity. After functionalization, the oxygen content increases between two and six times the original content of oxygen, higher as the surface area increases and as the strength of the treatment increases, that is, temperature and/or concentration of oxidizing reagent. Besides, these treatments lead to the removal of the growth catalyst from the carbon matter. The introduction of oxygen functionalities in the form of carboxyl, lactone, phenol and carbonyl/quinone does not affect significantly the textural properties of the raw carbon nanofibers, neither the graphite-like structure. Only the largest severe treatment $\left(\mathrm{HNO}_{3}: \mathrm{H}_{2} \mathrm{SO}_{4}\right.$, boiling temperature) on the $\mathrm{CNF}$ with the lowest graphitization degree leads to a destruction of the original morphology.

The introduction of surface oxygen groups on the surface of CNFs causes, in general, a decrease of the electronic conductivity. The largest decrease of ca. $75-90 \%$ is obtained after oxidizing with the most severe conditions: $\mathrm{HNO}_{3}: \mathrm{H}_{2} \mathrm{SO}_{4}$ at boiling temperature, which are also the conditions that create the largest number of oxygen containing groups. A decrease between $40-70 \%$ is obtained after oxidizing with $\mathrm{HNO}_{3}$ at boiling temperature. However, the 
oxidation at room temperature with $\mathrm{HNO}_{3}: \mathrm{H}_{2} \mathrm{SO}_{4}$ presents differences among CNFs: a decrease of conductivity in highly crystalline CNFs of ca. $50 \%$ whereas no reduction is obtained with the other two CNFs with a lower crystalline degree. Consequently, oxidizing CNFs at low temperature (room temperature) but using severe oxidizing reagents is beneficial in terms of electronic conductivity preservation and oxygen containing groups creation. Nevertheless, further studies are needed to determine the adequate treatment in terms of platinum deposition and fuel cell performance, since the behavior of the catalytic layer is a compromise among more variables. 


\section{Acknowledgments}

The authors wish to thank FEDER and the Spanish MICINN for financial support to project

MAT2008-06631-C01. D. Sebastián also acknowledges CSIC for his I3P (Ref. I3PPRE_06_00473) predoctoral grant. 


\section{References}

[1] Antolini E. Carbon supports for low-temperature fuel cell catalysts. Appl Catal, B 2009; 88(1-2):1-24.

[2] Joo SH, Pak C, You DJ, Lee SA, Lee HI, Kim JM, et al. Ordered mesoporous carbons (OMC) as supports of electrocatalysts for direct methanol fuel cells (DMFC): Effect of carbon precursors of OMC on DMFC performances. Electrochim Acta 2006; 52(4):1618-1626.

[3] Chang H, Joo SH, Pak C. Synthesis and characterization of mesoporous carbon for fuel cell applications. J Mater Chem 2007; 17:3078-3088.

[4] Calvillo L, Lázaro MJ, García-Bordejé E, Moliner R, Cabot PL, Esparbé I, et al. Platinum supported on functionalized ordered mesoporous carbon as electrocatalyst for direct methanol fuel cells. J Power Sources 2007; 169(1):59-64.

[5] Marie J, Berthon-Fabry S, Achard P, Chatenet M, Pradourat A, Chainet E. Highly dispersed platinum on carbon aerogels as supported catalysts for PEM fuel cell-electrodes: comparison of two different synthesis paths. J Non-Cryst Solids 2004; 350:88-96.

[6] Figueiredo JL, Pereira MFR, Serp P, Kalck P, Samant PV, Fernández JB.

Development of carbon nanotube and carbon xerogel supported catalysts for the electrooxidation of methanol in fuel cells. Carbon 2006; 44(12):2516-2522.

[7] Bessel CA, Laubernds K, Rodriguez NM, Baker RTK. Graphite nanofibers as an electrode for fuel cell applications. J Phys Chem B 2001; 105(6):1115-1118.

[8] Ismagilov ZR, Kerzhentsev MA, Shikina NV, Lisitsyn AS, Okhlopkova LB, Barnakov $\mathrm{ChN}$, et al. Development of active catalysts for low Pt loading cathodes of PEMFC by surface tailoring of nanocarbon materials. Catal Today 2005; 102-103:58-66.

[9] Lee K, Zhang J, Wang H, Wilkinson DP. Progress in the synthesis of carbon nanotube- and nanofiber-supported Pt electrocatalysts for PEM fuel cell catalysis. J Appl Electrochem 2006; 36(5):507-522. 
[10] Oh HS, Kim K, Ko YJ, Kim H. Effect of chemical oxidation of CNFs on the electrochemical carbon corrosion in polymer electrolyte membrane fuel cells. Int J Hydrogen Energy 2010; 35(2):701-708.

[11] Sebastián D, Calderón JC, González-Expósito JA, Pastor E, Martínez-Huerta MV, Suelves I, et al. Influence of carbon nanofiber properties as electrocatalyst support on the electrochemical performance for PEM fuel cells. Int J Hydrogen Energy 2010; doi:10.1016/j.ijhydene.2009.12.004.

[12] Matter PH, Zhang L, Ozkan US. The role of nanostructure in nitrogen-containing carbon catalysts for the oxygen reduction reaction. J Catal 2006; 239(1):83-96.

[13] Matter PH, Wang E, Arias M, Biddinger EJ, Ozkan US. Oxygen reduction reaction activity and surface properties of nanostructured nitrogen-containing carbon. J Mol Catal A: Chem 2007; 264(1-2):73-81.

[14] Chou JT, Sasaki K. Microstructural analysis of catalyst/catalyst support interfaces of PEFC electrocatalysts. Solid State Ionics 2008; 179(27-32):1405-1408.

[15] Watanabe M, Saegusa S, Stonehart P. High platinum electrocatalyst utilizations for direct methanol oxidation. J Electroanal Chem 1989; 271(1-2):213-220.

[16] Gasteiger HA, Kocha SS, Sompalli B, Wagner FT. Activity benchmarks and requirements for Pt, Pt-alloy, and non-Pt oxygen reduction catalysts for PEMFCs. Appl Catal, B 2005; 56(1-2):9-35.

[17] Nores-Pondal FJ, Vilella IMJ, Troiani H, Granada M, de Miguel SR, Scelza OA, et al. Catalytic activity vs. Size correlation in platinum catalysts of PEM fuel cells prepared on carbon black by different methods. Int J Hydrogen Energy 2009; 34(19):8193-8203.

[18] Frelink T, Visscher W, van Veen JAR. Particle size effect of carbon-supported platinum catalysts for the electrooxidation of methanol. J Electroanal Chem 1995; 382(12):65-72. 
[19] Taylor AD, Sekol RC, Kizuka JM, D'Cunha S, Comisar CM. Fuel cell performance and characterization of 1-D carbon-supported platinum nanocomposites synthesized in supercritical fluids. J Catal 2008; 259(1):5-16.

[20] Zaragoza-Martín F, Sopeña-Escario D, Morallón E, Salinas-Martínez de Lecea C.

$\mathrm{Pt} /$ carbon nanofibers electrocatalysts for fuel cells. Effect of the support oxidizing treatment. J Power Sources 2007; 171(2):302-309.

[21] Kim S, Park SJ. Preparation and electrochemical behaviors of platinum nanoparticles impregnated on binary carbon supports as catalyst electrodes of direct methanol fuel cells. J Solid State Electrochem 2007; 11(6):821-828.

[22] Guha A, Zawodzinski Jr. TA, Schiraldi DA. Evaluation of electrochemical performance for surface-modified carbons as catalyst support in polymer electrolyte membrane (PEM) fuel cells. J Power Sources 2007; 172(2):530-541.

[23] Guha A, Lu W, Zawodzinski Jr. TA, Schiraldi DA. Surface-modified carbons as platinum catalyst support for PEM fuel cells. Carbon 2007; 45(7):1506-1517.

[24] Zhang Y, Toebes ML, van der Eerden A, O'Grady WE, de Jong KP, Koningsberger DC. Metal particle size and structure of the metal-support interface of carbon-supported platinum catalysts as determined with EXAFS spectroscopy. J Phys Chem B 2004; 108(48):18509-18519.

[25] Hull RV, Li L, Xing Y, Chusuei CC. Pt nanoparticle binding on functionalized multiwalled carbon nanotubes. Chem Mater 2006; 18(7):1780-1788.

[26] Plomp AJ, Su DS, de Jong KP, Bitter JH. On the nature of oxygen-containing surface groups on carbon nanofibers and their role for platinum deposition-An XPS and titration study. J Phys Chem C 2009; 113(22):9865-9869.

[27] Ros TG, van Dillen AJ, Geus JW, Koningsberger DC. Surface oxidation of carbon nanofibres. Chem Eur J 2002; 8(5):1151-1162. 
[28] Toebes ML, van Heeswijk JMP, Bitter JH, van Dillen AJ, de Jong KP. The influence of oxidation on the texture and the number of oxygen-containing surface groups of carbon nanofibers. Carbon 2004; 42(2):307-315.

[29] Calvillo L, Lázaro MJ, Suelves I, Echegoyen Y, Bordejé EG, Moliner R. Study of the surface chemistry of modified carbon nanofibers by oxidation treatments in liquid phase. $\mathrm{J}$ Nanosci Nanotechnol 2009; 9(7):4164-4169.

[30] Ismagilov ZR, Shalagina AE, Podyacheva OY, Ischenko AV, Kibis LS, Boronin AI, et al. Structure and electrical conductivity of nitrogen-doped carbon nanofibers. Carbon 2009; 47(8):1922-1929.

[31] Pantea D, Darmstadt H, Kaliaguine S, Sümmchen L, Roy C. Electrical conductivity of thermal carbon blacks. Influence of surface chemistry. Carbon 2001; 39(8):1147-1158.

[32] Pantea D, Darmstadt H, Kaliaguine S, Roy C. Electrical conductivity of conductive carbon blacks: influence of surface chemistry and topology. Appl Surf Sci 2003; 217(14):181-193.

[33] Suelves I, Lázaro MJ, Moliner R, Echegoyen Y, Palacios JM. Characterization of $\mathrm{NiAl}$ and $\mathrm{NiCuAl}$ catalysts prepared by different methods for hydrogen production by thermo catalytic decomposition of methane. Catal Today 2006; 116(3):271-280.

[34] Lázaro MJ, Sebastián D, Suelves I, Moliner R. Carbon nanofiber growth optimization for their use as electrocatalyst support in proton exchange membrane (PEM) fuel cells. J Nanosci Nanotechnol 2009; 9(7):4353-4359.

[35] Sebastián D, Suelves I, Lázaro MJ, Moliner R. Carbon nanofibers as electrocatalyst support for fuel cells: Effect of hydrogen on their properties in $\mathrm{CH} 4$ decomposition. J Power Sources 2009; 192(1):51-56.

[36] Celzard A, Marêché JF, Payot F, Furdin G. Electrical conductivity of carbonaceous powders. Carbon 2002; 40(15):2801-2815. 
[37] Figueiredo JL, Pereira MFR, Freitas MMA, Órfão JJM. Modification of the surface chemistry of activated carbons. Carbon 1999; 37(9):1379-1389.

[38] Zhou JH, Sui ZJ, Zhu J, Li P, Chen D, Dai YC, et al. Characterization of surface oxygen complexes on carbon nanofibers by TPD, XPS and FT-IR. Carbon 2007; 45(4):785796.

[39] Montes-Morán MA, Suárez D, Menéndez JA, Fuente E. On the nature of basic sites on carbon surfaces: an overview. Carbon 2004; 42(7):1219-1225.

[40] van der Lee MK, van Dillen AJ, Geus JW, de Jong KP, Bitter JH. Catalytic growth of macroscopic carbon nanofiber bodies with high bulk density and high mechanical strength. Carbon 2006; 44(4):629-637.

[41] Toebes ML, Bitter JH, van Dillen AJ, de Jong KP. Impact of the structure and reactivity of nickel particles on the catalytic growth of carbon nanofibers. Catal Today 2002; $76(1): 33-42$.

[42] Euler KJ. The conductivity of compressed powders. A review. J Power Sources 1978; 3(2):117-136. 


\section{Figure captions}

Figure 1. Methane to carbon conversion for the three growth conditions of CNFs: CNF 1, 700

${ }^{\circ} \mathrm{C}$ and $4 \mathrm{~L} \mathrm{~g}_{\text {cat }}{ }^{-1} \mathrm{~h}^{-1}$; CNF 2: $600{ }^{\circ} \mathrm{C}$ and $4 \mathrm{~L} \mathrm{~g}_{\text {cat }}{ }^{-1} \mathrm{~h}^{-1}$; CNF 3: $550{ }^{\circ} \mathrm{C}$ and $10 \mathrm{~L} \mathrm{~g}_{\text {cat }}{ }^{-1} \mathrm{~h}^{-1}$.

Figure 2. SEM micrographs of (a) CNF 1; (b) CNF 1-A; (c) CNF 2; (d) CNF 2-C; (e) CNF 3;

(f) CNF 3-B.

Figure 3. Evolution of oxygen desorbed as (a) $\mathrm{CO}_{2}$ and (b) $\mathrm{CO}$ from CNFs, during the TPD experiments.

Figure 4. X-Ray Diffraction patterns of CNFs before and after oxidation treatments.

Figure 5. Thermogravimetric analyses in the oxidation in air of untreated and treated CNFs

(TPO): (a) CNF 1 related samples; (b) CNF 2 related samples; (c) CNF 3 related samples.

Figure 6. Variation of electronic conductivity with applied pressure: (a) CNF 1 related

samples; (b) CNF 2 related samples; (c) CNF 3 related samples.

Figure 7. CNF density variation with pressure.

Figure 8. CNF electronic conductivity versus density.

Figure 9. Influence of the oxygen total content on the electronic conductivity of CNFs. 


\section{Table captions}

Table 1. Composition of oxygen functional groups on the surface of CNFs, obtained from TPD analyses.

Table 2. CNF textural properties from nitrogen physisorption measurements.

Table 3. Electronic conductivity before and after functionalization. 